\title{
PENGARUH REFERENCE GROUPS DALAM PENGAMBILAN KEPUTUSAN MEMBELI KONSUMEN PRODUK KECANTIKAN
}

\author{
Kartika Yuniarti \\ Pusat Kajian dan Pengembangan Produk PPM Manajemen \\ E-mail: kartika.yuniarti@gmail.com \\ Abdus Somad \\ Pengembangan Produk dan SOP PPE PPM Manajemen \\ E-mail:abdussomadsr@gmail.com
}

\begin{abstract}
ABSTRAK
Tujuan penelitian ini adalah terpetakannya reference group paling kuat dalam pengambilan keputusan membeli konsumen produk kecantikan. Metode penelitian yang dilakukan adalah kuantitatif dengan pendekatan analis is deskriptif. Subjek penelitian adalah konsumen yang pernah membeli produk kecantikan. Berdasarkan hasil identifikasi yang dilakukan, dari 114 responden, 98,3\% merupakan pembeli produk kecantikan. 67,5\% responden mengeluarkan biaya Rp.100.001-Rp.500.000 untuk membeli produk kecantikan. Pihak yang mempengaruhi pembelian adalah teman, beauty reviewer, saudara, pasangan, dan orang tua. Hasil penelitian ini diharapkan dapat memberikan informasi mengenai siapa sajakah yang memiliki pengaruh paling kuat dalam pengambilan keputusan membeli konsumen produk kecantikan.
\end{abstract}

Kata Kunci:

reference group, purchasing decision, sales, consumer behavior, management

\begin{abstract}
ABSTRACK
The purpose of this study is the mapping of the most powerful reference group in the decision to buy consumer beauty products. The research method is quantitative with descriptive analysis approach. Subjects of consumer research who ever bought beauty products. Based on the results of identification conducted, of 114 respondents, $98.3 \%$ are buyers of beauty products. $67.5 \%$ of respondents spend Rp.100.001-Rp.500,000 to buy beauty products. Reference group that affect purchases are friends, beauty reviewer, kin, spouses, and parents. The results of this study are expected to provide information on who have the most powerful influence in decision making buy consumer beauty products.
\end{abstract}

Key words:

reference group, purchasing decision, sales, consumer behavior, management 


\section{PENDAHULUAN}

\section{Latar Belakang}

Hampir seluruh wanita di dunia ingin kosmetik umum sebesar $4 \%$. tampil cantik. Salah satu cara untuk mencapainya adalah dengan menggunakan produk kecantikan. Tingginya permintaan konsumen menjadi salah satu alasan industri kosmetik tetap tumbuh meskipun dalam keadaan krisis ekonomi. Saat ini perkembangan industri kosmetik Indonesia tergolong solid. Hal ini terlihat dari peningkatan penjualan kosmetik yang mencapai 14\% sejak tahun 2012 dari angka 8,5 triliun menjadi Rp 9,76 triliun, berdasarkan data Kementerian Perindustrian. (kemenperin.go.id, Oktober 2016).

Produk kecantikan dan perawatan tubuh global pada 2012 mencapai US\$ 348 miliar, tumbuh tipis US\$ 12 miliar dibanding tahun sebelumnya berdasarkan data Euro Monitor. Meskipun pada tahun 2012 perekonomian dunia masih diwarnai krisis keuangan seperti yang terjadi di kawasan Eropa, maupun perlambatan ekonomi China, produk-produk kecantikan bermerek terbukti masih dapat bertumbuh dengan solid. Produk kecantikan bermerek diprediksi tumbuh $6 \%$ tahun ini, lebih tinggi dari pertumbuhan produk

(manufakturindo.com, Juni 2016).

Persatuan Perusahaan Kosmetika

Indonesia (Perkosmi) memperkirakan tahun ini penjualan kosmetik dapat tumbuh hingga $\mathrm{Rp}$. 11,22 triliun, naik $15 \%$ dibanding proyeksi 2012 sebesar Rp 9,76 triliun. Dari sisi ekspor, industri kosmetik ditaksir tumbuh $20 \%$ menjadi US\$ 406 juta.

Nuning S Barwa, Ketua Umum Perkosmi, mengatakan pertumbuhan volume penjualan kosmetik ditopang oleh peningkatan permintaan, khususnya dari konsumen kelas menengah. Pertumbuhan penjualan kosmetik juga didorong oleh tren kenaikan penggunaan kosmetik oleh kaum pria. "Dulu pria tidak tertarik membeli produk perawatan kulit yang maskulin, tapi sekarang ketertarikan mereka tinggi", katanya. Peluang pasar kosmetik di Indonesia masih sangat besar. (kemenperin.go.id, Oktober 2016).

Perluasan pasar kosmetik yang kini mulai menjangkau kaum pria tak lepas dari perkembangan inovasi di industri kosmetik yang begitu cepat. Semakin banyak macam produk yang ditawarkan untuk merawat kulit. 
Produk-produk make up juga semakin bervariasi, seperti munculnya berbagai jenis lipstick dan bedak jenis baru yang semakin disesuaikan dengan kebutuhan konsumen. Banyaknya pilihan yang ada, tentunya membuat konsumen semakin kritis dalam memilih produk mana yang dirasakan paling cocok untuk mereka.

Selain dalam hal inovasi, reference group juga memegang peranan penting dalam aktifitas pemilihan merek. Reference group sendiri merupakan kelompok sosial yang dapat dijadikan acuan dalam mereferensikan atau menginformasikan sesuatu. Kelompok sosial itu sendiri dapat berupa teman, keluarga, dan sebagainya. Menurut William F. Arens "For advertisers, it's not enoughjust to know the personal processes of perception, learning and persuasion, and motivation. Important Interpersonal Influences affect, sometimes even dominate these processes. They also serve as guidelines for consumer behavior. These influences can best be categorized as the family, the society and the cultural environment of the consumer" (Arens, 2006).

Sehingga secara umum, sebagian besar konsumen mendapat informasi tentang produk tidak hanya dari sumber komersial saja, akan tetapi peran interpersonal bisa menjadi sangat efektif dalam pemilihan merek atau produk. Dengan melalui pengumpulan informasi ini, konsumen dapat mengetahui kelebihan dan kekurangan merek ataupun produk dengan kompetitornya.

Extended decision making melibatkan pencarian internal dan eksternal yang luas dan diikuti dengan evaluasi kompleks beberapa alternatif (Hawkins,2000). Ini adalah respon terhadap tingginya tingkat pembelian. Evaluasi pasca pembelian, keraguan, dan evaluasi menyeluruh menjadi aspek yang penting dalam keputusan yang diperpanjang. Peran kelompok referensi sangat berpengaruh terhadap pemberian saran suatu keputusan pembelian. Setiap hari konsumen akan lebih sering bertemu dengan kelompok referensi mereka, dengan waktu pertemuan yang sering maka konsumen juga membuat teman atau saudara mereka sebagai pembanding atau referensi dalam melakukan keputusan pembelian. Sehingga dalam menentukan pilihan merek produk kosmetik yang akan dibeli biasanya konsumen akan menimbang kelebihan dan kekurangan dari produk tersebut. Apakah 
produk tersebut sesuai dengan apa yang diharapkan atau tidak. Melalui reference group terkadang juga akan mempengaruhi pemilihan merek. Sehingga sangat penting mengetahui bagaimana peranan mereka terhadap keputusan membeli konsumen.

Hal inilah yang menjadi fokus utama dalam penelitian ini, tentang bagaimana peran reference group dalam pengambilan keputusan membeli merupakan suatu tindakan keputusan konsumen dalam membeli dan menggunakan suatu produk. Karena sangatlah penting bagi sebuah perusahaan untuk memperhatikan sikap konsumen terkait dengan bagaimana konsumen dan pereferensinya mengerti dan mempunyai asosiasi positif terhadap merek.

\section{Rumusan Masalah}

Berdasarkan paparan latar belakang di atas, dapat ditarik rumusan masalah sebagai berikut: "Siapa sajakah yang memiliki pengaruh paling kuat dalam pengambilan keputusan membeli konsumen produk kecantikan?"

\section{Tujuan Penelitian}

Dari rumusan masalah yang ditetapkan, diharapkan penelitian ini mampu memberikan kontribusi untuk industri kosmetik Indonesia dengan terpetakannya reference group paling kuat dalam pengambilan keputusan membeli konsumen produk kecantikan.

\section{Ruang Lingkup Penelitian}

Pada penelitian ini, yang dijadikan ruang lingkup penelitian adalah konsumen yang membeli produk kosmetik.

\section{TINJAUAN TEORI}

\section{Kerangka Teore tis}

\section{Reference Group}

Sebuah kelompok (group) merupakan kumpulan dari dua atau lebih orang-orang yang saling berinteraksi untuk mencapai tujuan yang sama. Tujuan tersebut bisa merupakan tujuan individu atau tujuan bersama. Di dalam perspektif pemasaran, masing-masing kelompok di mana konsumen menjadi anggotanya akan mempengaruhi perilaku pembelian dan konsumsi dari konsumen tersebut. Kelompok mempengaruhi proses pembelian dalam dua cara. Pertama, kelompok mempengaruhi pembelian yang dibuat oleh seorang konsumen. Kedua, anggota-anggota keompok seringkali membuat keputusan bersama-sama sebagai sebuah kelompok.

$$
\text { Reference group adalah seorang }
$$

individu atau sekelompok orang yang secara nyata mempengaruhi perilaku seseorang. 
Reference group digunakan oleh seseorang sebagai dasar untuk perbandingan atau sebuah referensi dalam membentuk respons afektif, kognitif dan perilaku. Reference group akan memberikan standar dan nilai yang akan mempengaruhi perilaku seseorang. Dalam perspektif pemasaran, kelompok acuan adalah kelompok yang berfungsi sebagai referensibagi seseorang dalam keputusan pembelian dan konsumsi.

Menurut Sumarwan (2003), jenis reference group dibedakan menjadi:

1. Menurut intensitas interaksi dan kedekatannya, yaitu: (1) kelompok primer; (2) kelompok sekunder.

2. Menurut legalitas keberadaan, yaitu: (1) kelompok formal; (2) kelompok informal.

3. Menurut status keanggotaan dan pengaruh, yaitu: (1) kelompok aspirasi; (2) kelompok disosiasi; (3) Primary or secondary; (4) Membership.

Reference group mempengaruhi anggotanya setidaknya dengan tiga cara. Mereka memperkenalkan perilaku dan gaya hidup baru kepada seseorang, mereka mempengaruhi sikap dan konsep diri, dan mereka menciptakan tekanan kenyamanan yang dapat mempengaruhi pilihan produk dan merek (Kotler\&Keller, 2009). Hal ini sependapat dengan jurnal-jurnal penelitian sebelumnya seperti yang dipaparkan oleh Rorlen (2007) bahwa kelompok acuan dapat memberikan tiga jenis pengaruh, Antara lain: (1) Pengaruh informasional (informational influence). Hal ini terjadi ketika seseorang/individu meniru perilaku dan pendapat dari anggota suatu kelompok acuan yang memberikan informasi yang berguna; (2) Pengaruh normatif (normative influence atau sering juga disebut utilitarian influence). Pengaruh ini terjadi ketika individu mengikuti ketentuan kelompok acuan dengan tujuan untuk memperoleh imbalan atau menghindari hukuman; (3) Pengaruh ekspetasi-nilai (value expressive influence). Hal ini terjadi ketika individu merasa turut memiliki dan membentuk nilai dan norma dari suatu kelompok.

\section{Keputusan Membeli}

Perilaku konsumen merupakan sebuah kegiatan yang menggunakan barang dan jasa termasuk di dalamnya terdapat proses pengambilan keputusan pada persiapan dan penentuan kegiatan tersebut. Perilaku konsumen yang ada tersebut akan 
mempengaruhi konsumen dalam memilih suatu brand produk yang akan melalui tahapan tertentu. Dalam proses pembelian, konsumen mencari alternatif-alternatif dari produk yang ingin dibeli dan melakukan evaluasi untuk membuat keputusan pembelian.

Sebagai hasil dari kegiatan evaluasi alternatif, konsumen mengarah pada niatan atau keinginan untuk membeli (purchase intention) dengan kecenderungan untuk membeli merek tertentu (Morrissan, 2010). Keputusan pembelian adalah tahapan selanjutnya setelah ada niat atau keinginan pembeli.
Ada lima tahap yang dilalui konsumen dalam proses pembelian, yaitu pengenalan masalah, pencarian informasi, evaluasi alternatif, keputusan pembelian dan perilaku pembelian. Model ini menekankan bahwa proses pembelian bermula sebelum pembelian dan berakibat jauh setelah pembelian. Setiap konsumen tentu melewati kelima tahapan ini untuk setiap pembelian yang mereka buat :
a) Pengenalan Masalah
b) Pencarian Informasi
c) Evaluasi Alternatif
d) Keputusan Membeli
e) Evaluasi Setelah Pembelian

\section{Kajian Penelitian Terdahulu}

Tabel 1.

Penelitian terdahulu

\begin{tabular}{|c|c|c|c|c|}
\hline No & Nama Peneliti & Judul Penelitian & Tahun & Hasil \\
\hline 1 & $\begin{array}{l}\text { Nela } \\
\text { Marghaniyata }\end{array}$ & $\begin{array}{l}\text { Peran Reference Group Dalam } \\
\text { Purchase Decision } \\
\text { (Studi deskriptif kualitatif pada } \\
\text { Pengguna Produk Asus } \\
\text { Mahasiswa Farmasi Universitas } \\
\text { Gajah Mada Yogyakarta) }\end{array}$ & 2012 & $\begin{array}{l}\text { Penelitian juga memperlihatkan } \\
\text { reference group mempunyai peran dalam } \\
\text { dalam pengambilan keputusan dalam } \\
\text { konsumen konsumen. }\end{array}$ \\
\hline 2 & $\begin{array}{l}\text { Agung } \\
\text { Kembau\& } \\
\text { Peggy Adeline } \\
\text { Mekel }\end{array}$ & $\begin{array}{l}\text { Reference Groups, Family, } \\
\text { Roles And Status On Young } \\
\text { Consumer Bahvior Towards } \\
\text { Purchase Intentions Of Luxury } \\
\text { Fashion Brands }\end{array}$ & 2014 & $\begin{array}{l}\text { Reference groups, keluarga, dan peran \& } \\
\text { status memiliki pengaruh signifikan } \\
\text { terhadap keputusan membeli konsumen } \\
\text { muda pada merek fashion premium. }\end{array}$ \\
\hline 3 & $\begin{array}{l}\text { Raka Randra } \\
\text { Rangkuti \& } \\
\text { Eka } \\
\text { Sulistyawati }\end{array}$ & $\begin{array}{l}\text { Pengaruh Social Influence Dan } \\
\text { Lifestyle Terhadap Niat } \\
\text { Membeli Pada Carrefour }\end{array}$ & 2014 & $\begin{array}{l}\text { variabel social influence dan lifestyle } \\
\text { secara parsial dan simultan berpengaruh } \\
\text { signifikan dan positif pada niat membeli } \\
\text { pada Carrefour. }\end{array}$ \\
\hline 4 & $\begin{array}{l}\text { Sara Linawati } \\
\& \text { Eristia Lidia } \\
\text { Paramita }\end{array}$ & $\begin{array}{l}\text { Pengaruh Persepsi Orang Tua } \\
\text { Tentang Keinginan Anak Dan } \\
\text { Anak Sebagai Pemengaruh } \\
\text { Terhadap Keputusan Beli } \\
\text { Orang Tua }\end{array}$ & 2015 & $\begin{array}{l}\text { Persepsi orang tua terhadap keinginan } \\
\text { anak memiliki pengaruh positif yang } \\
\text { signifikan terhadap keputusan membeli } \\
\text { orang tua. Anak memiliki pengaruh } \\
\text { negatif yang signifikan terhadap } \\
\text { keputusan membeli orang tua }\end{array}$ \\
\hline
\end{tabular}


Tabel 1. (Lanjutan)

Penelitian terdahulu

\begin{tabular}{|c|c|c|c|c|}
\hline No & Nama Peneliti & Judul Penelitian & Tahun & Hasil \\
\hline 5 & $\begin{array}{l}\text { Danupol } \\
\text { Hoonsopon } \\
\text { and Wilert } \\
\text { Puriwat }\end{array}$ & $\begin{array}{l}\text { The Impact of Reference Group } \\
\text { on Purchase Intention: A Case } \\
\text { Study in Distinct Types of } \\
\text { Shoppers }\end{array}$ & 2013 & $\begin{array}{c}\text { Utilitarian shoppers } \\
\text { memiliki kecenderungan untuk } \\
\text { melakukan pembelian ketika diberikan } \\
\text { informasi oleh private group. Namun, } \\
\text { reference group tidak memiliki pengaruh } \\
\text { terhadap purchase intention } \\
\text { pada hedonic and social shoppers }\end{array}$ \\
\hline 6 & $\begin{array}{l}\text { Deon Nel, } \\
\text { Leyland F. } \\
\text { Pitt, Pierre } \\
\text { Berthon, } \\
\text { Gerard } \\
\text { Prendergast }\end{array}$ & $\begin{array}{l}\text { Social decision schemes and } \\
\text { group } \\
\text { processes: some impacts on } \\
\text { decision making }\end{array}$ & 1996 & $\begin{array}{c}\text { Adanya hubungan antara lima variable } \\
\text { Green dan Taber sebagai evaluasi } \\
\text { interaksi pribadi antara } \\
\text { anggota kelompok bermain game } \\
\text { simulasi pemasaran, dan kinerjanya } \\
\text { permainan game simulasi. }\end{array}$ \\
\hline 7 & $\begin{array}{l}\text { Rui da Silva, } \\
\text { Gary Davies, } \\
\text { Pete Naudé }\end{array}$ & $\begin{array}{l}\text { Assessing the influence of retail } \\
\text { buyer variables on the } \\
\text { buying decision-making } \\
\text { process }\end{array}$ & 2002 & $\begin{array}{l}\text { Hasil riset menunjukkan konsumen } \\
\text { memiliki kriteria dalam membeli dan } \\
\text { keputusan membeli dipengaruhi oleh } \\
\text { karakteristik dari konsumen }\end{array}$ \\
\hline 8 & $\begin{array}{l}\text { Azmawani } \\
\text { Abd Rahman, } \\
\text { Ebrahim } \\
\text { Asrarhaghighi, } \\
\text { Suhaimi Ab } \\
\text { Rahman } \\
\end{array}$ & $\begin{array}{l}\text { Consumers and Halal } \\
\text { cosmetic products: } k \text { nowledge, } \\
\text { religiosity, attitude and } \\
\text { intention }\end{array}$ & 2015 & $\begin{array}{l}\text { Ditemukan penerimaan positif terhadap } \\
\text { produk kosmetik halal, serta niat } \\
\text { konsumen untuk memilih kosmetik halal } \\
\text { di kalangan konsumen Malaysia. }\end{array}$ \\
\hline 9 & $\begin{array}{l}\text { Nizar Souiden, } \\
\text { Mariam } \\
\text { Diagne }\end{array}$ & $\begin{array}{l}\text { Canadian and French men's } \\
\text { consumption of cosmetics: a } \\
\text { comparison of their attitudes } \\
\text { and motivations }\end{array}$ & 2009 & $\begin{array}{l}\text { Pria Prancis dan Kanada membeli } \\
\text { produk perawatan (kecantikan) namun } \\
\text { memiliki motivasi dan dorongan yang } \\
\text { berbeda saat mempertimbangkan } \\
\text { konsumsi dan pembelian produk } \\
\text { perawatan pria }\end{array}$ \\
\hline 10 & $\begin{array}{l}\text { Tendai } \\
\text { Chikweche, } \\
\text { John Stanton, } \\
\text { Richard } \\
\text { Fletcher }\end{array}$ & $\begin{array}{l}\text { Family purchase decision } \\
\text { making at the bottom of the } \\
\text { pyramid }\end{array}$ & 2012 & $\begin{array}{l}\text { Identifikasi perubahan dan beberapa } \\
\text { model pembelian keluarga, yang } \\
\text { dipengaruhi oleh kendala yang dihadapi } \\
\text { konsumen serta peran berbeda dari anak- } \\
\text { anak dalam keluarga }\end{array}$ \\
\hline
\end{tabular}

Kerangka Pemikiran Konseptual

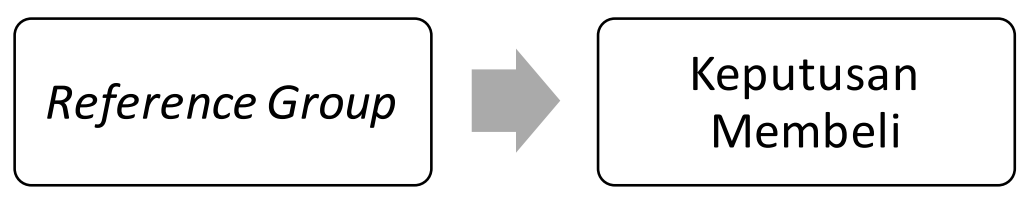

Gambar 1.

Kerangka pemikiran konse ptual 


\section{METODE RISET}

\section{Lokasi dan Waktu Penelitian}

Penelitian ini dilakukan di Jakarta dan sekitarnya. Penelitian ini berlangsung dari bulan Februari - Juli 2017.

\section{Pendekatan Penelitian}

Penelitian ini menggunakan pendekatan kuantitatif yang digunakan untuk meneliti pada populasi atau sampel tertentu. Pengumpulan data menggunakan instrumen penelitian, analisis data bersifat kuantitatif atau statistik, dengan tujuan untuk menguji hipotesis yang telah ditetapkan. Proses penelitian ini bersifat deduktif, dimana untuk menjawab rumusan masalah digunakan konsep atau teori.

\section{Teknik Pengumpulan Data dan Informasi}

Dalam melaksanakan penelitian yang telah dijelaskan sebelumnya, dibutuhkan informasi atau data yang terkait. Beberapa metode pengumpulan data yang dilakukan adalah:

\section{a. Data Primer}

Data primer yaitu data yang diperoleh secara langsung dalam penelitian. Data primer yang diperoleh menggunakan metode pengumpulan data berupa kuesioner dan interview.

b. Data Sekunder

Data sekunder yaitu pengumpulan data yang telah tersedia sebelumnya. Data sekunder menggunakan metode pengumpulan data berupa studi literatur dengan sumber literatur-literatur yang berkaitan, artikel, website internet dan materi perkuliahan.

\section{Teknik Sampling}

Teknik pengambilan sampel yang digunakan adalah purposive sampling, yaitu memilih sampel berdasarkan posisi dengan akses tertentu yang dianggap memiliki informasi yang berkaitan dengan permasalahannya secara mendalam dan dapat dipercaya untuk menjadi sumber data (Sutopo, 2006). Data yang digunakan dalam penelitian ini diperoleh dari 2 sumber yaitu data primer dan data sekunder. Data primer adalah informasi yang diperoleh dari tangan pertama (langsung) oleh peneliti. Data sekunder adalah informasi yang dikumpulkan dari sumber yang sudah ada (Sekaran dan Bougie, 2010). Data primer dalam penelitian ini diperoleh melalui kuesioner dan wawancara dengan konsumen yang pernah membeli produk kecantikan. Data sekunder diperoleh melalui studi literatur.

\section{Teknik Pengolahan dan Analisis Data}

Teknik pengolahan data penelitian ini menggunakan bantuan program software Statistical Packages for Social Science (SPSS) for Windows version 23.0 dan Gephi version 0.9.1. SPSS digunakan untuk mengklasifikasikan setiap jawaban dari butir pertanyaan pada kuisioner online. Sedangkan Gephi untuk membantu peneliti mengolah data dengan metode Social 
Network Analysis (SNA). Metode SNA merupakan sebuah metode untuk memetakan dan mengukur sebuah hubungan dan alur keterkaitan antar setiap orang-orang, kelompok, dan informasi lainnya (orgnet.com/SNA).

Dengan menggunakan SNA, diharapkan peneliti bisa menemukan keterkaitan antar data yang menggambarkan hubungan antara satu jawaban dengan jawaban dari pertanyaan lainnya pada hasil pengisian kuesioner. Dari keterkaitan ini akan diketahui pola/jaringan yang menunjukkan reference group yang paling memberikan pengaruh terhadap keputusan membeli produk kecantikan. Peneliti juga bisa menemukan hubungan antar aspek. Dari jaringan hubungan tersebut juga dapat dilihat tingkat kedalamannya serta aspek mana saja yang menjadi alasan terpenting dalam keputusan membeli produk kecantikan.

Metode analisis data pada penelitian ini adalah dengan menggunakan analis is deskriptif. Analisis deskriptif adalah sebuah metode yang berusaha mendeskripsikan, menginterpretasikan sesuatu, misalnya kondisi atau hubungan yang ada, pendapat yang berkembang, proses yang sedang berlangsung, akibat atau efek yang terjadi atau tentang kecenderungan yang sedang berlangsung.

\section{PEMBAHASAN}

Studi ini meneliti reference group paling kuat dalam pengambilan keputusan membeli konsumen produk kecantikan. Data diperoleh sebanyak 115 data tingkat konsumen dan 108 data reference group.

Profil 115 responden konsumen, 98,3\% responden pernah membeli produk kecantikan. Tidak hanya wanita, pria kini juga merupakan konsumen bagi produk kecantikan, dilihat dari adanya reponden pembeli berjenis kelamin pria sebesar $20 \%$. Usia responden mayoritas berada pada 2332 tahun (total 83,5\%), dan bersedia membeli produk kecantikan pada kisaran harga hingga Rp 500.000. pihak yang paling sering memberikan rekomendasi terhadap pembelian produk kecantikan adalah orang tua $(13,2 \%)$ dan pasangan $(11,4 \%)$. Produk kecantikan yang dibeli adalah make up (62\%) dan skincare (64\%).

\section{Hasil Gephi}

Menggunakan software Gephi 9.1, studi ini memetakan pengaruh reference group terhadap pembelian produk kecantikan. Berdasarkan pembahasan terhadap 108 data responden dan reference groupnya terdapat 116 nodes dan 207 edges. Berikut merupakan hasil pemetaan berdasarkan data yang dikumpulkan. 


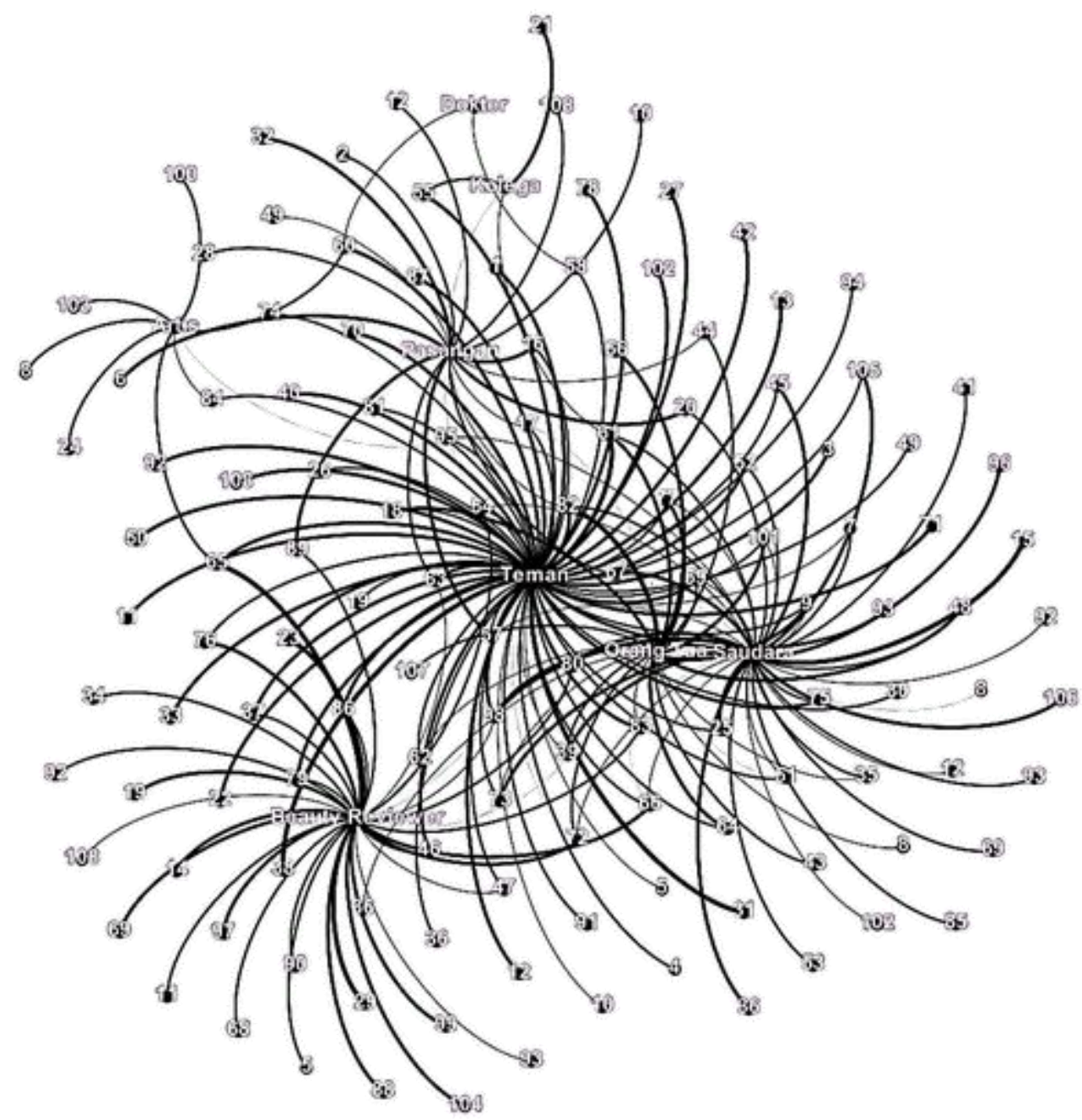

Gambar 2.

Hasil Pemetaan Data

Dari gambar di atas, dapat terlihat bahwa ada 5 pemain besar dalam penelitian ini yaitu teman, orang tua, saudara, beauty reviewer, dan pasangan. Teman memiliki edge weight paling besar. Hal ini mengindikasikan bahwa teman merupakan aktor kunci dalam grafik ini.

Berbeda dengan hasil olahan deskriptif yang menyebutkan bahwa orang tua merupakan pihak yang paling banyak memberikan rekomendasi, teman memiliki pengaruh paling kuat. Dilihat dari tingkat level yang mengacu kepada teman, sebagian besar merupakan degree tinggi, berupa garis lebih tebal. Reference group yang memberikan pengaruh yang kuat terhadap pembelian produk kecantikan adalah beauty reviewer dan saudara. Responden mengatakan bahwa mereka sering kali mencari review dari orang-orang di Instagram, Youtube, Blog, atau Beauty Forum sebelum membeli suatu produk. Rekomendasi dari saudara juga merupakan input penting bagi mereka, karena mereka 
merasa persamaan kecocokan dengan produk yang biasa digunakan oleh saudara mereka. Orang tua menempati posisi pengaruh keempat, dan pasangan menempati posisi pengaruh kelima terbesar dalam pengambilan keputusan membeli produk kecantikan.

\section{Diskusi}

Hal ini sesuai dengan penelitian sebelumnya, diketahui bahwa Reference Group memiliki peran dalam keputusan pembelian konsumen. Reference Group dapat bertindak sebagai inisiator yang berfungsi sebagai inisiator dalam pengambilan keputusan. Tapi tidak selalu Reference Group bisa bertindak sebagai inisiator dalam pembelian, karena dalam beberapa kasus posisi Reference Group yang bisa bertindak sebagai influencer group atau seseorang yang bekerja untuk mendorong seseorang mengikuti nasehat yang diberikan oleh Reference Group.

Penelitian ini mendukung penelitian yang dilakukan oleh Nadia Arfiani (2015) menjelaskan bahwa Reference Group berpengaruh secara positif dan signifikan secara simultan dan parsial. Selaras dengan pendapat Arfy (2015) menyebutkan bahwa Reference Group berpengaruh terhadap keputusan pembelian. Pengaruh Reference Group dalam pengambilan keputusan berperan dalam ketiga proses sebelumnya; pengenalan kebutuhan, pencarian informasi, evaluasi alternatif. Hal ini dapat dijelaskan dalam salah satu tahapannya, yaitu pencarian informasi. Konsumen mencari informasi mengenai produk yang akan dibeli melalui berbagai sumber. Sumber-sumber informasi menurut Kotler dan Keller (2009) ada empat; (1) pribadi; (2) komersial;

(3) publik; dan

eksperimental. Dari keempat sumber tersebut yang paling mempengaruhi konsumen adalah pribadi, yang mencakup keluarga, teman, rekan kerja, maupun tetangga.

\section{KESIMPULAN DAN SARAN}

\section{Kesimpulan}

Reference Group memiliki peran dalam keputusan pembelian konsumen. Reference Group dapat bertindak baik sebagai inisiator ataupun influencer sehingga seseorang terdorong untuk membeli produk kecantikan.

\section{Saran}

\section{Bagi Perusahaan}

1. Perlu untuk mengenali lebih jauh tentang bentuk produk yang diinginkan dari konsumennya. Pengetahuan mengenai merek apa saja yang beredar di pasaran menjadikan konsumen tidak memilih pada satu merek saja sehingga produsen harus bersedia mengeksplorasi temuan-temuan barunya terlebih lagi menciptakan trend 
Pengaruh Reference Group dalam Pengambilan... (Kartika Yuniarti \& Abdus Somad)

baru yang nantinya mampu diminati oleh

para konsumen serta mempertimbangkan

promosi dalam periklanan yang menggunakan Reference Group karena dapat mendorong konsumen untuk meniru merek yang dikonsumsi oleh Reference Group.
2. Mengantisipasi pada kebutuhan konsumen mencari variasi dengan cara meningkatkan inovasi produk.

Bagi Peneliti Selanjutnya

Disarankan agar memperluas atau mengkombinasikan variabel Reference Group dengan variabel lain, misalkan dari faktor kelas sosial, gaya hidup, brand image dan lain-lain. 


\section{DAFTAR PUSTAKA}

Arens, Wiliam F. 2006. Contemporary Advertising. New York: McGraw-Hill Companies Azmawani Abd Rahman, Ebrahim Asrarhaghighi, Suhaimi Ab Rahman. 2015. Consumers and Halal cosmetic products: knowledge, religiosity, attitude and intention. Journal of Islamic Marketing, Vol. 6 Issue: 1, pp.148-163, https://doi.org/10.1108/JIMA-09-2013-0068

Blackwell, RD., Engel, J.F., Miniard, P.W. 2006. Consumer behavior (9th ed.). USA : Harcourt. Durianto, Darmadi dkk, 2007. Strategi Menaklukkan Pasar. Yogyakarta: Penerbit PT Gramedia Pustaka Utama.

Febryan, Ferdhy. 2010. The Power of Selling. Jakarta: PT. Elex Media Komputindo.

Kembau, Agung \& Mekel, Peggy Adeline. 2014. Reference Groups, Family, Roles And Status On Young Consumer Bahvior Towards Purchase Intentions Of Luxury Fashion Brands. Jurnal EMBA 1169 Vol.2 No.2 Juni 2014, Hal. 1169-1179

HK Chi et al., 2009. The Impact of Brand Awareness on Consumer Purchase Intention : The Mediating Effect of Perceived Quality and Brand Loyalty. The Journal of International Management Studies, Volume 4, Number 1, February, 2009.

Nadia Arfeani, 2015. Pengaruh Persepsi Harga, Kualitas Produk Dan Reference Group Terhadap Keputusan Pembelian Pelumas Sepeda Motor Pertamina Enduro 4T Di Jakarta. Jurnal Penelitian Universitas Bakrie.

Nizar Souiden, Mariam Diagne. 2009. Canadian and French men's consumption of cosmetics: a comparison of their attitudes and motivations. Journal of Consumer Marketing, Vol. 26 Issue: 2, pp.97-109, https $/ /$ doi.org/10.1108/07363760910940465

Peter, J. Paul. \& Jerry C. Olson, 2008. Consumer Behavior : Perilaku Konsumen dan Strategi Pemasaran. Jakarta: Erlangga.

Schiffman, Leon G. dan Leslie Lazar Kanuk. 2010. Consumer Behavior Tenthm Edition. Pearson Education.

Sharmila Pudaruth, Thanika Devi Juwaheer, Yogini Devi Seewoo. 2015. Gender-based differences in understanding the purchasing patterns of eco-friendly cosmetics and beauty care products in Mauritius: a study of female customers. Social Responsibility Journal, Vol. 11 Issue: 1, pp.179-198, https://doi.org/10.1108/SRJ-042013-0049

Sugiyono. 2008. Metode Penelitian Bisnis Pendekatan Kuantitatif, Kualitatif dan R\&D. Bandung : Alfabeta.

Sumarwan, U. 2003. Perilaku konsumen: Teori dan penerapannya dalam pemasaran. Ghalia Indonesia, Jakarta.

Tendai Chikweche, John Stanton, Richard Fletcher. 2012. Family purchase decision making at the bottom of the pyramid. Journal of Consumer Marketing, Vol. 29 Issue: 3, pp.202-213, https://doi.org/10.1108/07363761211221738 
Pengaruh Reference Group dalam Pengambilan... (Kartika Yuniarti \& Abdus Somad)

Tjiptono, Fandy. 2007. Strategi Pemasaran. Edisi Kedua. Yogyakarta : Andi.

Widya Rizka Arfy dan Ilhamuddin, 2015. Pengaruh Reference Group Terhadap Pembelian

Produk Bermerek. Program Studi Psikologi. Malang : Universitas Brawijaya. 